\title{
Trace Elements in Critical Illness
}

\author{
Anil Agarwal ${ }^{a}$, Puneet Khanna ${ }^{\mathrm{a}}$, Dalim Kumar Baidya, \\ Mahesh Kumar Arora, ${ }^{a}$,
}

\begin{abstract}
Nutritional support of the critically ill patient includes daily provision of macronutrients and micronutrients including vitamins and trace minerals. Publications on nutrition support often emphasize macronutrient administration including proteins, fats, and carbohydrates. Although micronutrient supplementation is common practice, guidelines for their provision during critical illness are completely empiric. Trace elements are essential not only as intermediaries in metabolism but also for their potential roles in wound healing, cellular immunity, and antioxidant activity. This review is aimed at highlighting the important role of trace elements in the metabolic support of patients and also as pharmaconutrients in intensive care units. Future research in ICU nutrition should emphasize on the pharmaconutrient aspect of trace elements so as to determine the appropriate route, dose and timing of the intervention.
\end{abstract}

Keywords: Trace elements; Critical illness; Pharmaconutrients

\section{Introduction}

Nutritional supplementation has traditionally been considered as an important supportive care in critically ill patients. However recent research in critical care nutrition suggests that it can have a positive therapeutic impact on patient outcomes in the intensive care unit (ICU). Nutrition in terms

\footnotetext{
Manuscript accepted for publication May 17, 2011

${ }^{a}$ Department of Anesthesia, All India Institute of Medical Sciences, New Delhi, India

${ }^{\mathrm{b}}$ Corresponding author: Mahesh Kumar Arora, Department of Anesthesia and Intensive Care, 5th Floor, Teaching Block, All India Institute of Medical Sciences, New Delhi - 110029, India.

Email: mkarora442@gmail.com

doi:10.4021/jem24e
}

of adjunctive care is giving way to a new paradigm - pharmaco-nutrition, in which certain key nutrients are used to modulate the inflammatory cascades caused by critical illness and protect against oxidative stress [1]. Trace element supplementation based on their strong antioxidant potential and other beneficial effects has become an integral component of this evolving nutritional strategy.

Nutritional support of the critically ill patient includes supplementation of the daily requirements of macronutrients and micronutrients including vitamins and trace minerals. Trace minerals include macrominerals (calcium, magnesium, phosphorus, sulfur, etc.) and trace elements (defined as those existing in less than one part per million body weight, e.g., zinc, copper, manganese, selenium, iron, iodine, chromium, molybdenum, etc.). Macronutrient supplementation is usually emphasized but there is relatively sparse literature available focused on the immense importance of the key trace elements in specific situations. This review is aimed at highlighting the important role of trace elements in the metabolic support of patients and also as pharmaco-nutrients in intensive care units.

\section{Trace Elements as Nutritional Supplement: General Considerations}

\section{Assessment of trace element status in the critically ill pa- tient}

Trace element status in critical illness may be evaluated using biochemical, physiologic, and clinical parameters [2]. Despite certain limitations, biochemical laboratory assessment is most frequently used to assess micronutrient status. It includes static indices (concentration of trace elements in the blood, tissue, or plasma) as well as functional measures. Static indices include serum and leukocyte levels for zinc $(\mathrm{Zn})$, serum and urine levels of copper $(\mathrm{Cu})$ and cuproenzymes, serum assay for selenium (Se) and plasma iron, transferrin and ferritin levels to assess iron stores in the body. However, these measures are of limited significance to reflect accurate trace element status in critical illness. Measuring serum levels of trace elements is difficult and requires 
Table 1. Recommendation for Trace Elements in Critical IIIness

\begin{tabular}{lllll}
\hline \multirow{2}{*}{ Trace Element } & RDA & \multicolumn{2}{c}{ Standard Dose } & Additional Supplementation \\
\cline { 2 - 4 } Zinc & $15 \mathrm{mg}$ & $2.5-5 \mathrm{mg}$ & $11-19 \mathrm{mg} / \mathrm{L}$ & $10-30 \mathrm{mg} / \mathrm{day}$ \\
Selenium & $50-100 \mathrm{mcg}$ & $20-60 \mathrm{mcg}$ & $20-70 \mathrm{mcg} / \mathrm{L}$ & $100-400 \mathrm{mcg} / \mathrm{day}$ \\
Iron & $0-15 \mathrm{mg}$ & 0 & $12-20 \mathrm{mg} / \mathrm{L}$ & - \\
Copper & $900 \mathrm{mcg}$ & $300-500 \mathrm{mcg}$ & - & - \\
Manganese & $1.8-2.2 \mathrm{mg}$ & $60-100 \mathrm{mcg}$ & - & - \\
\hline
\end{tabular}

careful collection techniques, using special trace elementfree tubes [3]. Previous balance studies have demonstrated the unreliability of serum trace element levels [4]. Serum levels may indicate recently administered trace elements and reflect short term status but do not accurately indicate tissue levels. Functional measures of trace elements include leukocyte chemotaxis and alkaline phosphatase for $\mathrm{Zn}$, plasma glutathione peroxidase [GPx] assay for Se, lysyl oxidase for $\mathrm{Cu}$ and zinc protoporphyrin/heme ratio but these are also not reliable or practical.

\section{Absorption and interactions}

Zinc, iron and selenium are absorbed mainly in the duodenum and jejunum, while chromium and copper are absorbed in the ileum.

Several interactions exist between the different trace elements affecting absorption via the gut and need to be kept in mind. Zinc supplementation decreases copper absorption and vice versa. Iron administration with enteral nutrition decreases the absorption of $\mathrm{Cu}$ and $\mathrm{Zn}$ and can lead to zinc deficiency [5].

\section{Altered distribution and metabolism of trace elements during injury and acute phase response}

Trace elements are distributed in the body among certain dynamic pools like circulating, storage, and tissue pools. During the acute phase response subsequent to injury or sepsis, several factors such as fluid shifts, altered regulation of acidbase balance and reduced dietary intake can all affect the presence of a given nutrient within these pools [2].

Decreased absorption via the gastrointestinal tract, increased urinary losses and altered concentration of transport or binding proteins occur during acute severe illness and lead to altered bioavailability and requirements of trace elements. Inflammation results in release of cytokines through regulation of transcriptional factors and therefore, causes a rapid redistribution of zinc, iron, copper, and selenium within the body due to decreased levels of the serum-binding proteins albumin, macroglobulin, and transferrin, whereas ferritin and ceruloplasmin levels are increased [6-8].

Factors affecting trace element requirements in the intensive care unit

The spectrum of critical illness and patients' comorbidities affect trace element requirements. Geriatric patients, especially those in long-term care facilities are often trace element deficient and need early supplementation [9]. Certain disease processes alter trace element status. Patients with malignancies are susceptible to micronutrient deficiencies. Patients on hemodialysis or peritoneal dialysis often are deficient in trace elements ( $\mathrm{Se}, \mathrm{Zn}$ ) possibly due to loss in dialysate or adsorption by the filters $[10,11]$. Gastrointestinal losses (e.g., post-surgical patients with fistulas, diarrhea) result in deficiency of multiple trace elements, especially $\mathrm{Zn}$ and Se. Chylous leaks and fistulas lead to loss of large volumes of protein-rich fluid each day and result in deficiencies of selenium and other trace elements [12]. Parenteral nutrition is indicated in these situations and needs to be supplemented with these trace elements.

The extent of the procedures also affects the trace element status in post-surgical critically ill patients. Gastrectomy or terminal ileum resection may lead to iron deficiency. Micronutrient deficiencies have been reported after bariatric surgery for weight reduction, e.g., Fe and Zn deficiency after Roux-en-Y gastric bypass and gastric banding procedures [13-15]. The recommended trace element requirement in ICU is given in Table 1.

\section{Individual Trace Elements}

\section{Zinc}

The functions of zinc as an essential trace element include formation of metalloenzymes, protein metabolism, RNA 
conformation and membrane stabilization. The key metalloenzymes with zinc as a constituent are carbonic anhydrase, alkaline phosphatase, alcohol dehydrogenase and superoxide dismutase. It plays a crucial role in cellular growth and replication, rapid epithelialization, wound healing, cellular immunity, and protection against oxidative stress [16]. Disturbances in the metabolism of the trace elements such as zinc and copper occur during burn, trauma or sepsis which is manifested by increased urinary excretion of these minerals despite normal or low serum levels. It is further exaggerated significantly after major surgical procedures [17]. Zinc is largely protein bound and increased muscle catabolism after surgery or major traumatic injury contributes to zinc loss from the body and hence the need for its supplementation in these situations [18].

Zinc deficiency also occurs in the patients with pancreatitis, renal disease, alcoholism, high dose steroids, and excess gastrointestinal losses such as high output fistulas. It may be manifested as skin rash (characteristic acrodermatitis enteropathica), glucose intolerance, poor wound healing, hepatic dysfunction and diminished work capacity of respiratory muscles. An amount of $25 \mathrm{mg}$ /day of elemental zinc is usually recommended to meet the needs and to replace the urinary and cutaneous losses in critically ill adults [19]. However, additional zinc supplementation may be indicated for some patients (particularly in those with burns involving large surface area) who demonstrate poor wound healing or those with a preexisting deficiency [20]. Normal serum zinc level ranges from $70-150 \mathrm{mcg} / \mathrm{dl}$. Low serum alkaline phosphatase may be used as an indirect measure of zinc deficiency.

Zinc plays a crucial role in the development and regulation of the immune system and its deficiency may lead to depleted immunity and increased susceptibility to infections. Hence, pharmacologic zinc supplementation, in addition to standard dietary intake, has been used to enhance immune function [21]. In a randomized clinical trial involving critically ill patients, zinc, was provided during the first 8 days as part of a combined intravenous trace element supplement (containing about $26 \mathrm{mg} /$ day of zinc) and was found to be associated with a decrease in pulmonary infections and length of ICU stay. No adverse effects were noted with parenteral zinc supplementation in this study [22].

Zinc as a component of superoxide dismutase protects against oxidative stress by interacting with catalase and glutathione peroxidase. Excessive prolonged zinc intake may, in contrast, impair immune function and outcome in immunocompromised individuals. In vitro and in vivo studies demonstrate impaired chemotaxis and function of leukocytes. Copper deficiency has been noted with enteral zinc therapy [23]. Excess zinc intakes lead to severe copper deficiency, anemia, neutropenia, and leukopenia. Other manifestations of zinc toxicity include gastrointestinal symptoms (epigastric pain, nausea, vomiting), iron deficiency, altered lipoprotein metabolism, and decreased glucose clearance. Many of the adverse effects of high dose enteral zinc are alleviated with intravenous supplementation. However, parenteral zinc supplementation ( $30 \mathrm{mg}$ /day) in humans has also been reported to lead to an exaggerated acute phase response and increased levels of interleukin-6 [24]. In general, supplementation of two times the RDA is considered adequate and safe. In patients with increased zinc loss (pancreatitis, excess gastro-intestinal losses, renal disease, burns, HIV, malignancy), daily supplementation of $55 \mathrm{mg} /$ day may better accommodate the requirements. Patients with higher zinc supplement need to be monitored for serum copper and iron deficiency. Short term parenteral zinc therapy may also be considered as an alternative in these situations.

Additional supplementation may also be required in critically ill children with major burns and enteral intake of $25 \mathrm{mg}$ per day or parenteral dose of $50 \mathrm{mcg} / \mathrm{kg} /$ day has been recommended in children over three years of age.

\section{Copper}

Copper is important for wound healing, hematopoiesis and as an anti-oxidant. It is a co-factor for metalloenzymes involved with connective tissue cross-linking and norepinephrine synthesis [25]. It is poorly absorbed from the gastrointestinal tract and has low daily requirements. It is deficient in patients with long term parenteral or enteral nutrition and burns. Copper deficiency may be manifested as pancytopenia, myelopathy or peripheral neuropathy. The RDA for copper in adults is $900 \mathrm{mcg}$ and parenteral dose is $300-500 \mathrm{mcg}$ per day. In critically ill patients with hepatic insufficiency, $\mathrm{Cu}$ should be decreased or omitted from parenteral nutrition. Patients receiving parenteral copper supplementation may be needed to monitor serum copper to ceruloplasmin ratio to avoid hepatotoxicity. Although urinary copper excretion is further increased with copper supplementation, ceruloplasmin synthesis can be increased with higher copper intake [26]. Standard enteral nutritional supplements, when provided consistently at goal rate, seem adequate to meet the daily copper requirements in adults and children. However, in critically ill burn patients, supplemental copper intakes approximating $5 \mathrm{mg} /$ day in adults and $20 \mathrm{mcg} / \mathrm{kg} /$ day in children are necessary to compensate cutaneous losses.

\section{Selenium}

Selenium is a key component of the endogenous defense system against oxidative stress in human beings. It exists in two forms - selenomethionine (Se-Met) and selenocysteine (Se-Cys, the biologically active form). It is a constituent of glutathione peroxidase (GSH-Px), which acts as a free radical scavenger enzyme and inactivates hydrogen peroxide and fatty acid hydroperoxides. In addition, it aids in thyroid hormone production and inhibits nuclear transcription fac- 
tor expression. Serum selenium level and enzyme assay for GSH-Px are used as monitoring indices in the intensive care unit. Like other trace elements, plasma selenium levels are decreased during critical illness [27]. Selenium deficiency occurs in patients with bowel resection, gastro-intestinal fistulas, alcoholism, chylous leaks, HIV infection, and those undergoing venovenous hemodialysis. However, unlike trace elements such as zinc and copper, overall urinary excretion of selenium is not significantly elevated above normal limits during critical illness [28]. Increased selective uptake of selenium by injured tissues for defense against reactive oxygen species may explain the progressive decline in plasma and urinary levels.

The current RDA for selenium is $55 \mathrm{mcg} /$ day, as needed to maximize the GSH-Px activity. There is ample evidence for beneficial effect of selenium supplementation during critical illness. Low plasma values are inversely correlated with severity scores in the ICU. Supplementing routine nutritional therapy with an additional amount of $60 \mathrm{mcg} /$ day of selenium in patients after major trauma and a larger intake (190 mcg/day) as part of an intravenous trace element preparation in burn patients result in improved patient outcomes. In critically ill children, $2 \mathrm{mcg} / \mathrm{kg} /$ day of additional intravenous selenium supplementation has been recommended.

Selenium supplementation needs to be guided by indices of selenium deficiency [29]. Increased plasma and urinary selenium levels and maximization of GSH-Px activity are acceptable indicators of adequate replenishment. Supranormal intake may lead to easy fatigue, irritability, neuropathy and gastrointestinal symptoms. Maintaining sufficient levels of other anti-oxidants like vitamins E, C, and betacarotene can minimize reliance on selenium for antioxidant defense. In renal failure patients, plasma Se levels should be monitored. Se deficiency should be considered in patients with unexplained cardiac failure as its deficiency may cause cardiomyopathy leading to congestive heart failure and arrhythmias [30].

\section{Manganese}

Manganese serves as a component of superoxide dismutase and is also important for arginine and pyruvate metabolism. Mn deficiency may manifest as defective carbohydrate and lipid metabolism. An enteral intake of $1.8-2.3 \mathrm{mg}$ per day is considered acceptable while parenteral dose is $60-100 \mathrm{mcg}$ per day. Dose should be decreased in patients with hepatic insufficiency [31, 32].

\section{Iron}

Iron plays a central role in oxygen transport as the key component of the heme molecule and also other oxygen-carrying proteins including heme enzymes, myoglobin, and cytochrome $a-a_{3}$. As a constituent of the functional groups of many enzymes operating in the Krebs cycle, it is essential for energy metabolism. Enzymes like glutathione peroxidase, catalase, and a number of dehydrogenases need iron as a key element and hence it plays a crucial role in the body's defence against oxidative stress. Anemia during critical illness is multifactorial. The common causes of anemia in the ICU include increased destruction or impaired production of red blood cells combined with blood loss because of frequent diagnostic testing and operative procedures. Iron deficiency is also induced by cytokines during the inflammatory response [33]. Iron stores in the body are also diminished due to impaired absorption, nutrient antagonisms, and concomitant copper and vitamin A deficiencies.

There is conflicting evidence regarding the relationship between iron supplementation and infection. It has been shown to reduce respiratory infection rates and diarrheal episodes in anemic children. Decreased transferrin saturation in patients with major burns may lead to impairment of the erythropoietin response although serum erythropoietin levels are normal. Supplementing iron under these conditions can increase severity of infection and increase levels of free iron, which may be harmful as a chelator of free radical formation. Monitoring iron indices, particularly for a decreasing trend in ferritin, may be used to assess the timing and appropriateness of iron therapy.

\section{Trace Elements as Pharmaco-Nutrients}

Traditionally critical care nutrition has been viewed as a supportive care and not as an active therapeutic modality. However, the concept of pharamaco-nutrition is based on the impact of nutrients being greater than just the provision of nutrition alone and stressing their impact on specific patient outcomes. In accordance with the emerging concept of pharamaco-nutrition, the administration of key nutrients should be dissociated from the provision of supplemental nutrition so that their full dose can be delivered, and their therapeutic effects (immune modulation and antioxidant defense) can be assessed appropriately [34]. Trace elements like selenium and zinc are the key micronutrients along with glutamine and omega fatty acids which are being investigated in most recent trials on pharmaco-nutrition.

\section{Antioxidant Role of Trace Elements}

Oxidative stress caused by reactive oxygen species (ROS) is critical to the underlying pathophysiology of critical illness, especially the development of organ failure. During severe sepsis, mitochondrial dysfunction and ischemia-reperfusion injury may lead to increased generation of ROS and reactive nitrogen-oxygen species (RNOS). In critically ill patients, there are reduced stores of antioxidants, which have been 
associated with an increase in free radical generation, an augmentation of the systemic inflammatory response, subsequent cell injury, increased organ failure, and even higher mortality [35]. Depletion of antioxidants is directly proportional to the severity of trauma or sepsis. Antioxidants are part of a complex endogenous defence system designed to protect tissues from the damaging effects of oxidative stress caused by excessive amounts of ROS/RNOS. These include selenium, zinc, manganese, iron, vitamins $\mathrm{E}$ and $\mathrm{C}$, and glutathione which act as free radical scavengers and co-factors of crucial enzymes such as superoxide dismutase, catalase and glutathione peroxidase. A systematic review examining trials of antioxidant supplementation in critically ill patients has recently been conducted [36]. Thirteen studies were identified, most studied the effects of selenium either alone or in combination with other trace elements $(\mathrm{Zn})$ and vitamins (A, C and E). When the results of all the trials were aggregated, overall antioxidants were associated with a significant reduction in mortality related to improved organ function, but had no effect on infectious complications or ICU length of stay in critically ill patients. A recent large, multicenter randomized trial of high-dose selenium supplementation in 249 patients with severe systemic inflammatory response syndrome, sepsis, and septic shock demonstrated a large, but not significant, reduction in mortality. A greater treatment effect, however, was detected in patients with high normal levels of selenium compared with normal levels of selenium, indicating that selenium is having an effect beyond restoring a deficiency [37]. Selenium has been identified as the cornerstone of the endogenous defence against oxidative stress and serum selenium levels correlate inversely with the severity of sepsis. Selenoproteins play an essential role in improving cellular immune function, activation of thyroid hormones and regulation of DNA synthesis. This may explain the fact that of all the pharmaconutrients, selenium supplementation has been associated with the most favorable outcomes.

\section{Ideal Route, Timing and Dosage of Pharmaco- nutrient Administration}

In the evolving concept of pharamaconutrition, nutrients are treated as therapeutic agents rather than as part of a nutritional supplementation alone. Hence, like all new therapeutic modalities, there is a need to determine the most efficacious route, timing, duration and dosage of nutrient administration. However, there are no randomized trials published to date comparing enteral and parenteral delivery of pharmaconutrients, the most efficacious route remains to be determined and is a topic necessitating further research. Available evidence suggests that oxidative stress leading to mitochondrial dysfunction may become irreversible 48 hours after the onset of severe sepsis [38]. A decline in the cellular immune response occurs quite early with the onset of hyperinflammation and severe sepsis. Therefore, the antioxidant trace elements (Se, $\mathrm{Zn}$ ) should be started early on admission to the ICU in order to have a positive treatment effect.

The optimum dose of pharmaco-nutrients is also not yet determined. Studies using a higher than median dose of selenium (500 - $1000 \mathrm{mcg} /$ day) have been associated with a trend towards significant reduction in mortality, whereas studies using a lower dose of selenium had no effect on mortality. Extremely high doses, however, may be associated with adverse effects and hence further research and dosefinding studies on pharmaco-nutrients are required [39]. In this context, a phase I, single-center, dose-escalating study involving 28 critically ill patients was recently conducted which demonstrated that intravenous selenium $500 \mathrm{mcg} /$ day added to the $300 \mathrm{mcg} /$ day enteral supplement, resulted in a greater reduction in markers of oxidative stress and improved mitochondrial function with no apparent adverse effect on organ function [40]. The results of this dosing study suggest that selenium supplementation at high doses is safe and may be needed to positively affect patient outcomes in the ICU. Based on the concept of pharmaco-nutrition, a multicenter, double-blind randomized controlled trial named the REDOXS study (Reducing Deaths due to Oxidative Stress) has been initiated to assess the therapeutic effects of glutamine and antioxidants like selenium in mechanically ventilated critically ill patients [41]. The outcomes of this trial are expected to significantly guide the intensivists regarding the optimum route and dose of the trace elements as pharmaconutrients.

\section{Conclusion}

Supplementation of trace elements in critically ill patients should be considered as a crucial component of ICU care. This will not only correct the deficiencies present during critical illness but also their anti-oxidant potential and immunomodulating properties may improve the patient outcomes in severe sepsis. Future research in ICU nutrition should emphasize on the pharmaco-nutrient aspect of trace elements so as to determine the appropriate route, dose and timing of the intervention.

\section{References}

1. Dupertuis YM, Meguid MM, Pichard C. Advancing from immunonutrition to a pharmaconutrition: a gigantic challenge. Curr Opin Clin Nutr Metab Care 2009;12(4):398-403.

2. Prelack K, Sheridan RL. Micronutrient supplementation in the critically ill patient: strategies for clinical practice. J Trauma 2001;51(3):601-620.

3. Sriram K, Lonchyna VA. Micronutrient supplementa- 
tion in adult nutrition therapy: practical considerations. JPEN J Parenter Enteral Nutr 2009;33(5):548-562.

4. Howard L, Ashley C, Lyon D, Shenkin A. Autopsy tissue trace elements in 8 long-term parenteral nutrition patients who received the current U.S. Food and Drug Administration formulation. JPEN J Parenter Enteral Nutr 2007;31(5):388-396.

5. Kenny F, Sriram K, Hammond JB. Clinical zinc deficiency during adequate enteral nutrition. J Am Coll Nutr 1989;8(1):83-85.

6. Singh A, Smoak BL, Patterson KY, LeMay LG, Veillon C, Deuster PA. Biochemical indices of selected trace minerals in men: effect of stress. Am J Clin Nutr 1991;53(1):126-131.

7. Gitlin JD, Schroeder JJ, Lee-Ambrose LM, Cousins RJ. Mechanisms of caeruloplasmin biosynthesis in normal and copper-deficient rats. Biochem J 1992;282( Pt 3):835-839.

8. Schroeder JJ, Cousins RJ. Interleukin 6 regulates metallothionein gene expression and zinc metabolism in hepatocyte monolayer cultures. Proc Natl Acad Sci U S A 1990;87(8):3137-3141.

9. Johnson KA, Bernard MA, Funderburg K. Vitamin nutrition in older adults. Clin Geriatr Med 2002;18(4):773799.

10. Story DA, Ronco C, Bellomo R. Trace element and vitamin concentrations and losses in critically ill patients treated with continuous venovenous hemofiltration. Crit Care Med 1999;27(1):220-223.

11. Sriram K, Abraham G. Loss of zinc and selenium does not occur through peritoneal dialysis. Nutrition 2000;16(11-12):1047-1051.

12. de Berranger E, Colinet S, Michaud L, Cremer R, Fourrier C, Breviere GM, Turck D, et al. Severe selenium deficiency secondary to chylous loss. JPEN J Parenter Enteral Nutr 2006;30(2):173-174.

13. Ponsky TA, Brody F, Pucci E. Alterations in gastrointestinal physiology after Roux-en-Y gastric bypass. J Am Coll Surg 2005;201(1):125-131.

14. Abell TL, Minocha A. Gastrointestinal complications of bariatric surgery: diagnosis and therapy. Am J Med Sci 2006;331(4):214-218.

15. Kushner R. Managing the obese patient after bariatric surgery: a case report of severe malnutrition and review of the literature. JPEN J Parenter Enteral Nutr 2000;24(2):126-132.

16. Prasad AS. Zinc in growth and development and spectrum of human zinc deficiency. J Am Coll Nutr 1988;7(5):377-384.

17. Henzel JH, DeWeese MS, Pories WJ. Significance of magnesium and zinc metabolism in the surgical patient. II. Zinc. Arch Surg 1967;95(6):991-999.

18. Fell GS, Fleck A, Cuthbertson DP, Queen K, Morrison C, Bessent RG, Husain SL. Urinary zinc levels as an indi- cation of muscle catabolism. Lancet 1973;1(7798):280282.

19. Demling RH, DeBiasse MA. Micronutrients in critical illness. Crit Care Clin 1995;11(3):651-673.

20. Henzel JH, DeWeese MS, Lichti EL. Zinc concentrations within healing wounds. Significance of postoperative zincuria on availability and requirements during tissue repair. Arch Surg 1970;100(4):349-357.

21. Shankar AH, Prasad AS. Zinc and immune function: the biological basis of altered resistance to infection. Am J Clin Nutr 1998;68(2 Suppl):447S-463S.

22. Berger MM, Spertini F, Shenkin A, Wardle C, Wiesner L, Schindler C, Chiolero RL. Trace element supplementation modulates pulmonary infection rates after major burns: a double-blind, placebo-controlled trial. Am J Clin Nutr 1998;68(2):365-371.

23. Fosmire GJ. Zinc toxicity. Am J Clin Nutr 1990;51(2):225-227.

24. Braunschweig CL, Sowers M, Kovacevich DS, Hill GM, August DA. Parenteral zinc supplementation in adult humans during the acute phase response increases the febrile response. J Nutr 1997;127(1):70-74.

25. Solomons NW. Biochemical, metabolic, and clinical role of copper in human nutrition. J Am Coll Nutr 1985;4(1):83-105.

26. Cunningham JJ, Leffell M, Harmatz P. Burn severity, copper dose, and plasma ceruloplasmin in burned children during total parenteral nutrition. Nutrition 1993;9(4):329-332.

27. Forceville X, Vitoux D, Gauzit R, Combes A, Lahilaire $\mathrm{P}$, Chappuis P. Selenium, systemic immune response syndrome, sepsis, and outcome in critically ill patients. Crit Care Med 1998;26(9):1536-1544.

28. Berger MM, Cavadini C, Chiolero R, Dirren H. Copper, selenium, and zinc status and balances after major trauma. J Trauma 1996;40(1):103-109.

29. Misra S, Kirby DF. Micronutrient and trace element monitoring in adult nutrition support. Nutr Clin Pract 2000;15:120-125.

30. Johnson RA, Baker SS, Fallon JT, Maynard EP, 3rd, Ruskin JN, Wen Z, Ge K, et al. An occidental case of cardiomyopathy and selenium deficiency. N Engl J Med 1981;304(20):1210-1212.

31. Dickerson RN. Manganese intoxication and parenteral nutrition. Nutrition 2001;17(7-8):689-693.

32. Casaer MP, Mesotten D, Schetz MR. Bench-to-bedside review: metabolism and nutrition. Crit Care 2008;12(4):222.

33. Walter T, Olivares M, Pizarro F, Munoz C. Iron, anemia, and infection. Nutr Rev 1997;55(4):111-124.

34. Jones NE, Heyland DK. Pharmaconutrition: a new emerging paradigm. Curr Opin Gastroenterol 2008;24(2):215222.

35. Quasim T, McMillan DC, Talwar D, Sattar N, O’Reilly 
DS, Kinsella J. Lower concentrations of carotenoids in the critically ill patient are related to a systemic inflammatory response and increased lipid peroxidation. Clin Nutr 2003;22(5):459-462.

36. Heyland DK, Dhaliwal R, Suchner U, Berger MM. Antioxidant nutrients: a systematic review of trace elements and vitamins in the critically ill patient. Intensive Care Med 2005;31(3):327-337.

37. Angstwurm MW, Engelmann L, Zimmermann T, Lehmann C, Spes CH, Abel P, Strauss R, et al. Selenium in Intensive Care (SIC): results of a prospective randomized, placebo-controlled, multiple-center study in patients with severe systemic inflammatory response syndrome, sepsis, and septic shock. Crit Care Med 2007;35(1):118126.

38. Levy RJ, Deutschman CS. Cytochrome c oxidase dysfunction in sepsis. Crit Care Med 2007;35(9
Suppl):S468-475.

39. Forceville X, Laviolle B, Annane D, Vitoux D, Bleichner G, Korach JM, Cantais E, et al. Effects of high doses of selenium, as sodium selenite, in septic shock: a placebo-controlled, randomized, double-blind, phase II study. Crit Care 2007;11(4):R73.

40. Heyland DK, Dhaliwalm R, Day A, Drover J, Cote H, Wischmeyer P. Optimizing the dose of glutamine dipeptides and antioxidants in critically ill patients: a phase I dose-finding study. JPEN J Parenter Enteral Nutr 2007;31(2):109-118.

41. Heyland DK, Dhaliwal R, Day AG, Muscedere J, Drover J, Suchner U, Cook D. REducing Deaths due to OXidative Stress (The REDOXS Study): Rationale and study design for a randomized trial of glutamine and antioxidant supplementation in critically-ill patients. Proc Nutr Soc 2006;65(3):250-263. 